Esta mística deve apostar na vida, acreditando que a morte não tem a última palavra. Apostar na vida é acreditar que os índios, negros, mulheres, crianças, enfim os excluídos do mercado mundial são a epifania de Deus na história. $\mathrm{Na}$ sua luta de resistência, vão forjando novos valores que podem contribuir para a construção de uma alternativa que possa incluir todos na vida. A busca de uma convi- vência humana em que a vida seja dom comum de todas as pessoas. Esta é uma mística que busca a inclusão de todos e por isso mesmo, está na base deste projeto alternativo que se busca construir.

Pe. Benedito Ferraro, é Doutor em Teologia Dogmática c Professor na Faculdade de Teologia N. S. da Assunção, e Vice-diretor na PUC de Campinas.

End.: Rua Macarai, 299, Vila Cura D'Arns 13045-170 Campinas - SP

\title{
LA TOMA DE DECISIONES EN LOS COMITÉS DE ÉTICA. LA PERSPECTIVA PAULINA DEL \\ DISCERNIMIENTO
}

Leonardo Belderrain

Normalmente, ante todas las circunstâncias dilemáticas en que se observam conflictos, el camino que lleva al juicio de conciencia, se realiza a través del cauce del discernimiento.

Para que el discernimiento funcione corretamente, es necesario atenerse a una técnica peculiar, tanto en la preparación, como en el desarollo y en la evaluación. Pero esta técnica ha de estar transitada por un "espiritu".

Este "espiritu de discernimiento", se tratará de describir en el horizonte de la cosmovisión judeocristiana por su importancia y su vigencia en la matriz de las culturas occidentales.

\section{Discernimiento: Perspectiva Biblica}

El verbo discernir (en griego, dokimazein) "es la clave de toda moral testamentaria", como lo afirman O. Culmann y el exégeta católico C. Spick.

La mayor relevancia del verbo está puntualizada en la obra de Pablo, donde posee un sentido moral en dos pasajes:
"No os amoldéis a este mundo, sino dejaos transformar por una nueva mentalidad, para ser Uds, capaces de discernir lo que es la voluntad de Dios, lo bueno, conveniente, acabado" (Rm 12,2).

"Pido en mi oración que vuestro amor crezca más y más en penetración y en sensibilidad para todo, a fim de discernir lo mejor, así serán sinceros y llegarán sin tropiezos al dia de Cristo. colmados de este fruto de rectitud que viene por Jesucristo, para gloria y alabanza de Dios" (Flp 1,9-11).

A nuestro modo de entender, en estos dos pasajes se expoen los elementos que integran el espíritu de discernimiento. Tales factores pueden ser agrupados en dos polaridades: una subjetiva y otra objetiva.

* La polaridad subjetiva, es que el cristiano es capaz de discernir en la medida en que se deja transformar por la nueva mentalidad (Rm 12,2).

El discernimiento moral se basea en la metamorfosis cristiana del sujeto moral. San Pablo explicita el significado de esta transformación 
del siguiente modo (Flp 1,9-11): El discernimiento moral brota del amor, al acrecentares éstes en penetración y en sensibilidad.

El discernimiento moral se es considerado como una manifestación de un sentido del tacto afinado por un intenso amor de caridad (C. Spick).

* La polaridad objetiva: el cristiano no hace discernimiento sobre una ley exterior objetiva, ni sobre principios morales abstractos. El objeto y el objetivo del discernimiento moral es la voluntad de Dios ( Rm 12,2).

Esta voluntad divina es descubierta a través de la incersante búsqueda de lo bueno, conveniente y acabado (Rm 12,2); y mediante la realización de lo mejor (Flp $1,10)$.

El hallazgo y la asimilación de la voluntad divina, trae como consecuencia:

a. Negativa del inconformismo cristiano: no os amoldéis a este mundo ( $R m$ 12,2);

b. Positiva: así serán sinceros y llegarán sin tropiezos al dia de Cristo, colmados de ese fruto de rectitud que viene por Jesucristo, para gloria y alabanza de Dios (Flp 1,10-11).

\section{Pespectiva Antropologica- Teologica}

La ética actual ha incorporado suficientemente las perspectivas personalistas de la cultura actual. El discernimiento ético es impensable hoy día, si no se tienen en cuenta los tópicos personalistas de la hora actual.

La decisión moral brota del núcleo autónomo de la persona. Una decisión ética únicamente tiene sentido cuando es respon-sable, es decir, cuando es una respuesta del yo ante las exigencias de su propria realización.

Por otra parte, la decisión moral se expresa de modo prevalente a través de opciones y actitudes; no mediante actos atomizados y casuísticos.

El discernimiento ético se instala preferentemente en la opción fundamental, y desde ahí orienta todo el dinamismo moral humano.

Además, la decision moral sin dejar de tener en cuenta la función secundaria de las instancias exteriores (ley, autoridad, tradiciones, etc.), las valora como ayuda para realizar un discernimiento ético realista y contrastado.

Las actuales orientaciones personalistas que estudian el discernimiento ético, procuran no caer en la tentación del subjetivismo es-. téril, del narcisismo ingenuo y de aquel individualismo que se exacerba en lo autogratificante.

La auténtica visión personalista de la decisión moral, sitúa el discernimiento ético en el lugar marcado por la reciprocidad de las conciencias y por las exigencias del proyecto histórico socialmente compartido.

Además de la perspectiva personalista anotada, el discernimiento ético suele asumir las perspectivas que provienen de la crítica social. La crítica y la sospecha son horizontes imprescindibles para entender hoy los procesos de decisión moral.

En la modernidad Marx y Freud pusieron de relieve cómo detrás de los procesos morales se esconden ideologizaciones opresoras u objetivaciones de una inmadurez neurótica, socialmente compartida.

Al subrayar la importancia de la perspectiva - erítica _. en - la configuración del discernimiento ético, se pone de relieve en la nueva - cultura - la - función sociopolítica de la decisión moral. Frente a una consideración preponderantemente intimista e individual 4 del discer-nimiento, comienza a legitimarse la funcionalidad social y material del mismo.

Dé esta forma, la estructura del empeño sociopolitico, puede ser pensada y vivida desde la categoria del discernimiento.
De este modo, el discernimiento ético logra distinguir entre el espíritu de liberación de los excluídos y el espíritu de opresión de los poderosos, ya que si se desvincula el acto del discernimiento de la articulación que la práctica política que realizan quienes se identifican con las periferias, dicho discernimiento no tendrá pautas o criterios reales concretos históricos, con qué realizar su interpretación estimativa.

\section{La Filosofia de los Comités de Ética}

La dialéctica amo-esclavo, generada sobre todo en estructuras esclerotizadas, puede ser descripta en una medicalización de la cultura, donde el poder económico y cultural se esgrimem en la relación con el enfermo. La conflictiva aumenta cuando en la complejidad de una enfermedad o de un nuevo tratamiento, o en el uso de un recurso escaso (órganos, sangre), resulta mucho más difícil delimitar quién es el más pobre, quién es el periférico, desde qué centro de poder se habla; quizás el ejemplo más claro al respecto han sido los dilemas causados por el SIDA, en los que era común que entrasen en conflicto los enfermeros, los hemofílicos, los grupos homosexuales. 
Discernir en estos casos en cómo privilegiar a los pobres, exigía ejercer una ética "en comisión", que permitiese - desde la representatividad y la ponderación inmediata de las situaciones - tomar decisiones.

Para quienes integran los $\mathrm{Co}$ mités de Ética, movidos por el espíritu cristiano, queda latente la pergunta de Cuál es la contribución desde el ethos específico del cris tianismo para el dîscernimiento en estos foros?

Esto se tratará de responder en la conclusión, tras describir previamente como interactúan tales Comités en la realidad hospitalaria.

\section{El Discernimiento en los Comités de Ética}

Los comités de Ética constituyen un modelo aceptable y altamente promisorio para tratar los graves problemas que han surgido como consecuencia del rápido incremento del saber médico, y de una tecnologia puesta al servicio del cuidado de la salud.

Se trata, por cierto, de un ejemplo de cooperación apto para evaluar dentro del marco de una ética de la responsabilidad situaciones complejas que exigen difíciles tomas de decisión por parte de los médicos, profesionales de la salud, pacientes o familiares de los mismos, científicos que investigan en el área biológica.

Actualmente existe una opinión más bien difundida que el principio de publicidad de las acciones es un criterio necesario para garantir la justicia, pero en más de un caso se observa que nos es un criterio suficiente para la toma de decisiones morales en lo que hace al discernimiento concreto de las situaciones conflictivas señaladas.

Lo que se ha llegado a consensuar de dichos comités es que se incluya a individuos considerados legos en relación al saber médico, esto es pacientes, familiares e incluso de la opinión pública. Ante esta realidad, se plantea generalmente esta objeción: Cómo pueden los legos comprender la complejidad de los problemas?, Puede el público elaborar juicios sólidos sobre temas de decisión médica?

Creemos posible afirmar que los criterios para la toma de decisión y los juicios en los cuales estos se expresan, han de ser realmente éticos, entonces los legos no están necesariamente menos entrenados que los científicos, ya que la evaluación objetivamente adecuada de los hechos y las consecuencias probables de nuestras acciones y: omisiones para la vida humana, sólo constituyen una parte imprescindible por cierto de un conflicto moral genuino, la otra parte supone intereses e ideales un pugna, y distintos tipos de actitudes frente a los hechos en cuestión.

La conciencia objetiva y neutra no alcanza a resolver los conflitos morales. Pruebla de ello es que los mismos científicos y médicos, han sido en muchos casos, quienes solicitaron la creación de comisiones y comités y otras formas de regulación. Ahora bien, existe un alto grado de consenso acerca de que todos los interesados deben participar en el proceso de elaboración de la toma de decisión.

Existe un alto grado de consenso acerca de que todos los interesados deben participar en el proceso de elaboración de las tomas de decisión, sin embargo no hay unanimidad de criterios sobre el modo de alcanzar el acuerdo. A nuestro entender, si el procedimiento de acuerdo es de carácter ético o moral, entonces, en primer lugar debe tratarse de algo más que de una simple estrategia de negociación entre los intereses de las partes que reemplace los argumentos morales por consideraciones puramente pragmáticas. En segundó lugar, no debe ser aceptada la tesis de la supuesta trivialidad de la reflexión ética, tesis que se basea o bien en una equi- paración de la moral con un mero problema se supervivencia, convirtiendo a esta última en el único criterio intersubjetivamente válido para la toma de decisiones en pro o en contra de ciertas acciones; o bien en la creencia en que las conclusiones éticas se dan en forma inmediata cuando se ha realizado una evaluación cientificamente correcta y completa de la situación y sus consecuencias.

La propuesta de una ética de la comunicación, como la formularán Karl Appel o Jürgen Habermas, consiste en que sólo se legitiman las normas y la única forma de llegar a un consenso intersubjetivo y libre de coerción es el verdadero diálogo, el discurso critico o la comunidad de comunicación.

El modelo ideal, según Apel para resolver los conflictos éticopolítico es el de cooperación en la comunidad de argumentación, cooperación que en principio posibilita hacer valer mediante argumentos las necesidades y los intereses, esto es las pretensiones de los afectados u manejar al mismo tiempo las informaciones relativas a la situación, especialmente el conocimiento de los expertos ecerca de las probables consecuencias de nuestras acciones. Y para que el análisis de la situación sea completo, sería necesario también hablar de ideales 
en conflicto; ya que estos constituyen un elemento de mucho peso en las discusiones morales.

Por razones de brevedad, y por considerar que se trata de los aspectos de la ética comunicativoconsensual más relevantes para nuestra propuesta de fundamentación de los Comités de Ética, sólo hacemos referencia a aquello que Apel denomina normas o reglas ideales que deben aceptar todos aquellos que entran en el discurso argumentativo de maneira seria, aunque somos concientes de que con ello sólo proponemos una visión parcial de la doctrina.

Em primer lugar, todo aquel que acepte intervenir en diálogo - y nosotros consideramos que los Comités pueden ser un ejemplo de esta situación -, deben compartir la creencia acerca de que es posible resolver los problemas reales de la vida práctica por medio de argumentos racionales, so pena de quedar excluído de las reglas del juego moral. Según Apel aquellos que ingresan seriamente en la comunidad de argumentación, como lo hacía Sócrates, por ejemplo deben suponer que en principio es posible responder argumentati. vamente los conflictos prácticos.

En segundo lugar, verdadera comunicación significa diálogo auténtico, esto es, un dialegein, un discurrir del uno con el otro, que culmina en la elaboración recíproca del discurso. Reciprocidad no implica necesariamente que todos los argumentos deban manejar igual cantidad y tipo de informa-ción; pues es bien sabido que el diálogo también supone diferencias. Pero si implica que se excluya el monopolio de la interrogación, el uso de argumentos retóricos, a fin de lograr efectos perlocucio-narios, las amenazas de violencia, etc. Pues otra de las condiciones o reglas normativas del discurso argumentativo, afirma que deberá ser separada de la comunidad de comunicación toda racionalidad estratégica destinada simplesmenle a negociar entre los individuos considerados como sistemas de autoafirmación.

En tercer lugar, existe una norma ética fundamental apta para hacer una diferencia entre diálogo y pseudo diálogo ella prescribe la reciprocidad generalizada de derechos y deberes, como Apel dice, "adjudicar iguales derechos y deberes de preguntar toda clase de cuestiones relativas a cualquier tópico concebible a todos los miembros posibles de la comunidad de comunicación". Y agrega que los tópicos a discutir deben ser fruto de un consenso. Un pseudo-diálogo no significa necesariamente asimetria en el manejo de la infor- mación o en el poder de construción del discurso crítico, sino antes bien, ausencia de reciprocidad.

Para concluir digamos lo siguiente: somos concientes de que nos movemos en el plano ideal y regulativo, pues es bien sabido que los argumentantes nunca se encuentran en esa condición ideal de diálogo y que siguen siendo hombres reales con sus propias convicciones. Pero justamente en ello reside, a nuestro entender, la función principal de los Comités de ética: en fijar las normas ideales del discurso que regulan la búsqueda de un posible consenso acerca de cuestiones prescriptivas que no se expresan simplemente en pergunta del tipo: Qué hago'? sino. Qué debo hacer? Y todo aquel que planta seriamente dilemas en términos de deber, por el mismo significado de la palabra deber, sabe que no está requiriendo respuestas meramente estratégicas, sino que de algún modo ha aceptado la posibilidad de limitar la estrategia para dar lugar a la moral. Y esto es lo mínimo que puede esperarse de un Comité que, no por casualidad, se llama Comité de Ética.

Para concluir, quisiera agregar una última regla limitativa a esta comunídad ideal de comunicación: la exclusion de los ideales e interesés no generalizables. Regla que, repitiendo palabras del mismo
Apel, podríamos formular del siguiente modo: "Obra sólo según una máxima que te ponga en condiciones de tomar parte en la fundamentación discursiva de aquellas normas cuyas consecuencias para todos los afectados fueran aptas para lograr un consenso".

\section{Criterios de racionalidad teologica para la toma de decisiones}

Parece inevitable llamar "teono-mía" a esta forma de fundamentar. Algunos autores piensan que puede existir una contradicción entre una fundamentación teónoma y la legislación que sanciona, pues el motivo de la acción moral vendría a ser extrínseco y el imperativo que expresara la actitud moral, sólo podría ser hipotético (del tipo "si quiere sostentar el cieclo, y evitar el infierno, actúa de tal manera"). Pero es bastante claro que lo más esencial del mensaje evangélico antes evocado, no se deja reducir a un modelo así.

Pablo se ha encargado en dar a conocer su tesis en la cuestión de los ídolos tan ampliamente debatida en la Carta a los Corintios y en la Carta a los Romanos se le asigna synaidesis no sólo el papel de alabar o acusar al agente moral, sino el de la mediación anticipativa, que hace responsabilizarse de 
antemano de lo que se va a hacer, discerniendo concretamente cuál es, atendido todo lo que es pertinente, la actuación buena, la actuación conforme con el principio del supremo amor. A esta posición ha sido fiel en teoría la tradición cristiana de teologia moral; aunque quizás ha puesto muchas veces tanta insistencia en la necesidad de la formación de la conciencia, según normas objetivas y autoridad, que ha podido reducir en exceso la realidad de dicho primado.

Es interesante apuntar marginalmente que, en un punto que era más relevante en la concepción kantiana formal de la ética que lo hubiera sido en otras, fueron de hecho los desarrollos explícitos de Kant.

En la perspectiva que hemos adoptado como la adecuada para una ética personalista, no pierden importancia las normas objetivas, no serán ahora un conjunto de objetividades (código fijo) que se imponga heterónoamente a la conciencia. Tampoco podrán se deducciones propriamente tales, obtenidas a partir del supremo principio moral. Pienso que el mejor modo de concebirse una ineludible función y donde se reconoce el primado de la conciencia, es cómo las pautas de conducta que normalmente seguirá la conciencia auténticamente amante en unas determinadas circunstâncias.

\section{REVISTADE}

El discernimiento que debe hacer la conciencia, es arduo, y muchas veces nada claro, incluso quien vive movido por el amor, buscará ayudas para el discernimiento. De allí que los Comités de Ética Hospitalarios, no sean patrimonio exclusivo de los cristianos, sino de qualquier persona que vea necesario, para actuar con prudencia, entrenarse en el discernimiento. Sentirá la necesidad de dialogar con los otros humanos las pautas morales de elección, de contar con esas pautas de modo razonable, estable, para que puedan usarlas otros en situaciones análogas. Las normas morales, según esto, nunca estarán escritas en ningún lugar, ni en un cielo platónico de valores, ni en un código humano de ningún tipo.

Su objetividad, hay que decir, surge por intersubjetividad. Podrían concebirse como el desencantado ideal del proceso histórico de buenas conciencias que han amado y han discernido cómo es más adecuado amar en cada circunstancia.

\section{Conclusion}

De lo señalado por San Pablo, el discernimiento concreto no debe hacerse sobre una ley exterior, ni sobre principios morales abstractos, sino que debe provenir - para el cristiano - de discernir en cada momento cuál es la voluntad de Dios para su vida.
De ello podría deducirse que para aquellos que ejercen una moral laica, se consideraría suficiente el respeto por la conciencia; siempre y cuando no traicione el bien común, y en el caso de que así lo fuese, bajo aquella ponderación que desde el consenso legitimase que no va en desmedro del más indefenso, del más débil.

El hecho de que para el cristiano su discernimiento ético parta de la instalación que éste possa en su opción fundamental, no le resta dramaticidad al ejercicio de la toma de decisión, ni lo exime del ejercicio del diálogo con todas las partes imbricadas en el dilema.

La incesante búsqueda de lo bueno, conveniente y acabado, desde la ética confesional cristiana, podrá exigirse y elucidarse a partir de aquellos que posean una ascética que parta de la vivencia de la Palabra de Dios en cada momento.

El cristiano se hará cargo de todas las consecuencias que puedan deducirse de la ética del discernimiento de la razón comunicativa, favorecerá la participación de todas las partes a la hora de argumentar, pero dará credibilidad a la misma en la medida en que dicha confrontación considere - desde su visión particular -, a los que inmediatamente se le presenten como excluídos del todo.

En temas tan contrastantes y conflictivos como distribuir recursos y benefícios de salud, resulta difícil determinar en cada momento particular cuál es la voluntad de Dios.

La sabiduría para el cristiano seguirá siendo un Don del Espíritu Santo, y el obrar prudente, estará precedido por la virtud de la docilidad de espíritu y por aquella humildad que desde un sano realismo permite a los hombres opinar sin ser dogmáticos y recibir un consejo, y quizás ésta sea la aportación más importante de la ética cristiana al discernimiento en los Comités de Ética'.

1. Para profundizar este tema, se sugiere la siguiente bibliografia: Austgen, R. J. "Natural Motivation in the Pauline Epistles", Notre Dame, 111. 1966; Drane, J. W. "Tradition, Law and Ethics in Pauline Theology: N T 16 (1974) 167-178; Duncan, D. L. "The Sayings of Jesus in the Churches of Paul", Oxford, 1971; Gibbs, J. G. "Creation and Redemption. A Study in Pauline Theology (NTS XXVI), 1971; Fjärdstedt, B., "Synoptic Tradition in 1 Corinthians", Uppsala, 1974; Herr, Th. "Naturrecht aus der kritischen Sicht des $\mathrm{N} \mathrm{T",} \mathrm{1976;} \mathrm{Holtz,} \mathrm{T.,} \mathrm{"Zur} \mathrm{Frage} \mathrm{der}$ inhaltlichen Weisungen bei Paulus": Th. LZ 106 (1981) 385-400'Hübner, H. "Das Gesetz bei Paulus" (FRLANT 1 19), 1980; Joest, W. "Gesetz und Freihet. Das Problem des Tertius usus legis bei Luther un die ntl. Parainese", 1968; Lillic, W, 12-23; Pedersen, S. "Agape-der eschatologische Hauptbegriff bei Paulus", en "Dic paulinische Literatur und Theologie, 1980, 159-186; Schürmann, H. "Das Gesetz des Christus" (Gal 6,2) Jesu Verhalten und Wort als letztgültige sittliche Norm nach Paulus, en F. S. R. Schackenburg, 1974, 282-300; Osborn, E. F. "Paul and Plato in Second Century Ethics" en Studia Patristica XV/I, Berlin, 1984, 474-485. 